\title{
Diseño Del Manual De Certificación De Las Estaciones REPARADORAS Para la estandarización de procedimientos de mantenimiento de productos aeronáuticos de la Fuerza Aérea Colombiana
}

El propósito de esta investigación es se-

-ñalar la normatividad y procedimientos que se necesitan para elaborar el Manual de Certificación de las Estaciones Reparadoras

\section{IDENTIFICACION GENERAL DEL PROYECTO}

PROGRAMA

ESPECIALIZACIÓN EN LOGÍSTICA AERONÁUTICA

TÍTULO

INVESTIGACIÓN

ESTRUCTURA AERONÁUTICA DE MATERIALES

$A ́ R E A$

FUNCIONAL LOGÍSTICA AERONÁUTICA para la Estandarización de Procedimientos en el Mantenimiento de Productos Aeronáuticos de la Fuerza Aérea Colombiana, cuyo propósito es certificar los procesos de las estaciones reparadoras y suministrar al personal de la Jefatura Técnica y de los Grupos Técnicos en las diferentes unidades las herramientas que servirán para evaluar periódicamente y/o certificar las estaciones reparadoras en Colombia, que prestan sus servicios de mantenimiento para mejorar los niveles de calidad y generar una operación segura de las aeronaves con las que cuenta la Fuerza Aérea. Asimismo, el uso del manual permitirá al personal de mantenimiento de las aeronaves y sus componentes tener un respaldo técnico en la toma de decisiones amparadas en los distintos procesos de certificación.
En la elaboración del manual se tomó como marco de referencia la normatividad de la Organización de Aviación Civil Internacional (OACI), la normatividad norteamericana, europea y la experiencia de los autores en el sector aeronáutico. Asimismo, se realizó una investigación de carácter documental, porque el objeto de estudio exigía la consulta de las diferentes normas, procedimientos, regulaciones establecidas y convenios mundiales, así como las disposiciones de mantenimiento en la operación de las aeronaves, lo que constituyó el insumo para conocer e interpretar las normas y los estándares internacionales que suministraron las bases técnicas para el funcionamiento de las estaciones reparadoras y con ellas evaluar los parámetros que actualmente se aplican en la Fuerza Aérea.

Con los análisis y hallazgos documentales realizados se encontró que era necesario que las estaciones reparadoras de la FAC, reorientaran algunos procesos a través de la documentación técnica que permita en un futuro optimizar y a su vez certificar los procesos de mantenimiento de las estaciones reparadoras; y así estar a la vanguardia de la aeronáutica internacional. De ahí, que se establecieron los contenidos del manual con el reglamento, procedimientos y formatos de acuerdo con los estándares internacionales con el fin de realizar una gestión competitiva y que responda a las necesidades de la aeronáutica nacional e internacional. 